\title{
Outcome of Sellar and Suprasellar Brain Tumors with Retractorless Modified Subfrontal Approach
}

\author{
ABDUL RAUF 1 , HAMEED ULLAH KHAN², MUBARAK HUSSAIN ${ }^{3}$ \\ ${ }^{1,3}$ Assistant Professors, Department of Neurosurgery, Liaquat University of Medical \& Health Sciences, Jamshoro \\ ${ }^{2}$ Assistant Professor, Department of Neurosurgery, Indus Medical College, Tando Muhammad Khan \\ Correspondence to Dr. Abdul Rauf, E-mail: raufmemondr@gmail.com Cell: 0333-2781800
}

\begin{abstract}
Aim: To determine the outcome of sellar and suprasellar brain tumors with retractorless modified subfrontal approach.

Study design: Descriptive/observational study

Place and duration of study: Department of Neurosurgery, Liaquat University Hospital Hyderabad/Jamshoro from $1^{\text {st }}$ March 2020 to $28^{\text {th }}$ February 2021.

Methodology: Fifty patients of sellar and suprasellar brain tumors age between 15-70 years were enrolled. Patients details demographics age, sex and body mass index were recorded after taking written consent. The inter-hemispheric front-basal technique was used for all patients and the average follow-up time was 6 months. Postoperatively, magnetic resonance imaging (MRI) and computerized tomography $(\mathrm{CT})$ scans in all patients were performed. After 12 hours, the postoperative CT scan was performed to monitor for persistent tumor and hemorrhage cerebral edema following an operation.

Results: There were $30(60 \%)$ male patients and $20(40 \%)$ female patients. Mean age of the patients were $28.36 \pm 14.88$ years with mean BMI $23.16 \pm 7.54 \mathrm{~kg} / \mathrm{m}^{2}$. Most of the patients $20(40 \%)$ were from age group $15-30$ years, followed by $31-40$ years in 12 (24\%) patients. Frequency of pituitary adenoma was found in 22 (44\%) cases, craniopharyngioma found in $19(38.7 \%)$ cases, arachnoid cyst found in $4(8 \%)$, keratin flakes in 2 (4\%) cases, benign giant cell tumor found in $2(4 \%)$ olfactory groove meningioma in $1(2 \%)$ and epidermoid in $1(2 \%)$ cases. Post operatively 35 (70\%) patients were completely recovered, complications found in 13 (26\%) patients who were recovered later and frequency of not recovered patients was $2(4 \%)$. According to Karnofsky performance, $16(32 \%)$ patients had scale 30 , scale 60 was in $2(4 \%)$ cases, scale 70 in $4(8 \%)$ patients, scale 80 in $19(38 \%)$ and scale 90 in $9(18 \%)$.

Conclusion: This retractorless method is very effective and safe in the sellar and suprasellar region for excision of big tumors. This method allows the huge tumor to be removed without serious complication.

Keywords: Sub-frontal approach, Sellar, Suprasellar, Brain tumor, Retractorless method
\end{abstract}

\section{INTRODUCTION}

The pituitary gland, which is slightly above sella turcica, is regulated by the hypothalamus. The inner carotid arteries; cranial nerves III, IV and VI; and the cranial nerve divisions $\mathrm{V}$ are found within the cavernous sinus. The hypophysis runs through the diaphragm sella and contains the neural veins and processes on the pituitary hormones are produced different endocrine cell types include thyroidstimulating hormone (TSH), prolactin, growth hormone $(\mathrm{GH})$, follicular-stimulating hormone $(\mathrm{FSH})$ and luteinizing hormone $(\mathrm{LH})$ are secreted by the anterior hipophysis. Post-hypophysis secrets antidiuretic (ADH) hormone and oxytocin. ${ }^{1-9}$

The annual incidence of hypophysiologic adenoma per 1 million people is between $10 \%$ and $15 \%$ of intracranial primary tumors. Hypophysical tumors of less than $10 \mathrm{~mm}$ of diameter are referred to as microadenoms, more than $10 \mathrm{~mm}$ macroadenomas, and more than $4 \mathrm{~cm}$ tumors are referred to as gigantic adenoms. In middle-aged women, microadenomas arise and also in elderly age men macroadenomas arise. About $30 \%$ of hypophysical tumors are categorized as non-functioning adenomas and show pressure sensations ${ }^{4}$.

Received on 13-03-2021

Accepted on 28-06-2021
On plain radiography, we could distinguish and widen the sella and doubled sellar floors. The size and location of the lesion and its connection with surrounding structures is demonstrated by magnetic resonance imaging. Studies reported that computed tomography scan is very helpful to see the sphenoid sinus architecture..$^{10,11}$

The first-line treatment approach for unfunctioning adenomas is regarded as an endoscopic transsphenoidal tumor excision. A transcranial technique is employed with considerable supratentorial tumor growth, following surgery at least 4 to 6 weeks after the surgery should be performed ${ }^{12-14}$.

The objective of the study was to determine the outcome of sellar and suprasellar brain tumors with retractorless modified subfrontal approach

\section{MATERIALS AND METHODS}

This descriptive cross-sectional study was conducted at Department of Neurosurgery, Liaquat University Hospital Hyderabad/Jamshoro from $1^{\text {st }}$ March 2020 to $28^{\text {th }}$ February 2021 after approval from Ethical Committee. This study comprised of 50 patients. Patients details demographics age, sex and body mass index were recorded after taking informed written consent. Patients with history of operated pituitary tumors and those did not give written consent were excluded. Patients were aged between 15-70 years. The inter-hemispheric front-basal technique was used for all 
patients and the average follow-up time was 6 months. Postoperatively, MRI and CT scans in all patients were performed. After 12 hours, the postoperative CT scan was performed to monitor for persistent tumor and hemorrhage cerebral edema following an operation. Complete data was analyzed by SPSS 20.

\section{RESULTS}

Thirty (60\%) patients were males and $20(40 \%)$ were females. Mean age of the patients were $28.36 \pm 14.88$ years with mean BMI $23.16 \pm 7.54 \mathrm{~kg} / \mathrm{m}^{2}$. Most of the patients $20(40 \%)$ were from age group $15-30$ years, $12(24 \%)$ patients were between $31-40$ years, $10(20 \%)$ were between $41-50$ years and $8(16 \%$ ) were $>50$ years (Table 1 ).

The pituitary adenoma was found in $22(44 \%)$ cases, craniopharyngioma found in $19(38 \%)$ cases, arachnoid cyst found in $4(8 \%)$, keratin flakes in $2(4 \%)$ cases, benign giant cell tumor found in $2(4 \%)$ olfactory groove meningioma in $1(2 \%)$ and epidermoid in $1(2 \%)$ cases (Table 2$)$.

According to Karnofsky performance, 16(32\%) patients had scale 30 , scale 60 was in $2(4 \%)$ cases, scale 70 in $4(8 \%)$ patients, scale 80 in $19(38 \%)$ and scale 90 in $9(18 \%)$ [Table 3]. Post operatively 35(70\%) patients were completely recovered, complications found in $13(26 \%)$ patients who were recovered later and frequency of not recovered patients was 2 (4\%) [Table 4].

Table 1: Baseline details demographics of enrolled cases $(n=50$

\begin{tabular}{|l|c|c|}
\hline Variable & No. & $\%$ \\
\hline Gender & 30 & 60.0 \\
\hline Male & 20 & 40.0 \\
\hline Female & \multicolumn{2}{|c|}{} \\
\hline Age (years) & 20 & 40.0 \\
\hline $15-30$ & 12 & 24.0 \\
\hline $31-40$ & 10 & 20.0 \\
\hline $41-50$ & 8 & 16.0 \\
\hline$>50$ & $28.36 \pm 14.88$ \\
\hline Mean age & $23.16 \pm 7.54$ \\
\hline Mean BMI & \multicolumn{2}{|c|}{} \\
\hline
\end{tabular}

Table 2: Occurrence of tumors among enrolled cases $(n=50)$

\begin{tabular}{|l|c|c|}
\hline Variable & No. & $\%$ \\
\hline Pituitary adenoma & 22 & 44.0 \\
\hline Craniopharyngioma & 19 & 38.0 \\
\hline Arachnoid cyst & 4 & 8.0 \\
\hline Keratin flakes & 2 & 4.0 \\
\hline Benign giant cell tumor & 1 & 2.0 \\
\hline Olfactory groove meningioma & 1 & 2.0 \\
\hline Epidermoid & 1 & 2.0 \\
\hline
\end{tabular}

Table 3: Association of Karnofsky Performance scale $(n=50)$

\begin{tabular}{|l|c|c|}
\hline Karnofsky Score & No. & $\%$ \\
\hline 30 & 16 & 32.0 \\
\hline 60 & 2 & 4.0 \\
\hline 70 & 4 & 8.0 \\
\hline 80 & 19 & 38.0 \\
\hline 90 & 9 & 18.0 \\
\hline
\end{tabular}

Table 4: Frequency of post-operative outcomes $(n=50)$

\begin{tabular}{|l|c|c|}
\hline Outcome & No. & $\%$ \\
\hline Recovered & 35 & 70.0 \\
\hline Complication & 13 & 26.0 \\
\hline Not recovered & 2 & 4.0 \\
\hline
\end{tabular}

\section{DISCUSSION}

Supracellular cancers that assault the huge sinus in particular are more attracted by a transcaveral frontotemporal approach. ${ }^{15,16}$ The best long-term results of patients can be added to tumor extraction in the main setting. The large size of tumors, greater the chances of harm to the cerebral structures that are necessary. ${ }^{17} \mathrm{~A}$ subtemporal technique is used for removing malignancies from the back of the fossa. ${ }^{18}$ Although this methodology may indeed damage the worldly outlook and care is tight and poorly arranged.

In the present study, $30(60 \%)$ patients were male and $20(40 \%)$ were females. Mean age of the patients were $28.36 \pm 14.88$ years with mean BMI $23.16 \pm 7.54 \mathrm{~kg} / \mathrm{m}^{2}$. Our findings were comparable to the previous study. ${ }^{19}$ Most of the patients $20(40 \%)$ were from age group 15-30 years. In $47 \%$ of patients, Baskin and Wilson ${ }^{20}$ used subfrontal technique. The results demonstrate that the tumor has been aggregated in just seven patients, six of whom did not repeat tumor removal. Nevertheless, $91 \%$ of the patients slacken and two kick the bucket. This test means that radiation is a satisfactory treatment for malignancies through subtotal evacuation and showed that 35 (70\%) patients were completely recovered, complications found in $13(26 \%)$ patients who were recovered later and frequency of not recovered patients was $2(4 \%)$. This was comparable to the previous study. ${ }^{21}$

In a study of 144 patients, Yasargil and colleagues ${ }^{22}$ used different techniques. In $90 \%$ of the patients, up to tumor extraction was performed and $7 \%$ again. It proposes the best long-term results for patients to obtain vital aggregate tumor expulsion. Then early determination when the tumor is still small, improves the probability of completed expulsion and achieves remarkable results.

We noticed that pituitary adenoma was found in 22 (44\%) cases, craniopharyngioma found in 19 (38\%) cases, arachnoid cyst found in $4(8 \%)$, keratin flakes in $2(4 \%)$ cases, benign giant cell tumor found in $2(4 \%)$ olfactory groove meningioma in 1 (2\%) and epidermoid in $1(2 \%)$ case. ${ }^{19}$ Karnofsky performance scale was used in our study. Sharma and Sawarkar ${ }^{23}$ presented that awareness of the requirement for early diagnostic imaging and developments in the various imaging modalities allow for an early diagnosis if the lesions are still of moderate dimension and thus can be processed using microscope or an endoscope with minimally invasive techniques. Progress in neuronavigation and endoscopic equipment allowed for treatment with less stressful methods of these lesions via fewer surgical pathways. A minimum access but similarly invasive and direct way for central skull base tumors to get exposed is an endoscopic endonasal approach and no brain retraction is necessary ${ }^{24-26}$.

In another study, Shirane et $\mathrm{al}^{27}$ presented that the fronto-basal interhemispheric approach is appropriate for removing craniopharyngiomas that extend out of sellarsuprasellar regions even through a narrow craniotomy window. Using this strategy, the pituitary stalk, structures hypothalamic and perforating agents can be removed without substantial sequelae associated to the surgical technique. This method provides a safe and minimally invasive method of craniopharyngioma treatment. 


\section{CONCLUSION}

This retractorless method is very effective and correct in the sellar and suprasellar region for excision of big tumors. This method allows the huge tumor to be removed without serious disease.

\section{Conflict of interest: Nil}

\section{REFERENCES}

1. Pirahanchi Y, Tariq MA, Jialal I. Physiology, thyroid. StatPearls [Internet] 2018

2. Patel H, Tiwari V. Physiology, posterior pituitary. StatPearls [Internet] 2018.

3. Shahid Z, Singh G. Physiology, hypothalamus. StatPearls [Internet] 2018.

4. Monson JP. The epidemiology of endocrine tumours. Endocrine Relat Cancer 2000; 7(1):29-36.

5. Al-Shraim M, Asa SL. The 2004 World Health Organization classification of pituitary tumors: what is new? Acta Neuropathologica 2006; 111(1):1-7.

6. Asa SL, Kovacs K. Clinically non-functioning human pituitary adenomas. Canadian J Neurol Sci 1992;19(2):228-35.

7. Snyder PJ. Clinically nonfunctioning pituitary adenomas. Endocrinol Metab Clin North Am 1993; 22(1):163-75.

8. Greenman Y, Melmed S. Diagnosis and management of nonfunctioning pituitary tumors. Ann Rev Med 1996;47:95106.

9. Flickinger JC, Nelson PB, Maninez AJ, et al. Radiotherapy of nonfunctional adenomas of the pituitary gland: results with long term follow-up. Cancer 1989;63:2409-14.

10. Elster AD. Imaging of the sella: anatomy and pathology. In: Seminars in ultrasound, CT and MRI. Philadelphia: Saunders, 1993; 14(3): 182-94.

11. Chiang MF, Brock M, Patt S. Pituitary metastases. Neurochirurgia 1990;33(04):127-31.

12. Mortini P, Losa M, Barzaghi R, Boari N, Giovanelli M. Results of transsphenoidal surgery in a large series of patients with pituitary adenoma. Neurosurgery 2005;56(6):1222-33.

13. Alleyne CHJ, Barrow DL, Oyesiku NM. Combined transsphenoidal and pterional craniotomy approach to giant pituitary tumors. Surg Neuro 2002;57:380-90.

14. Ragel BT, Couldwell WT. Pituitary carcinoma: a review of the literature. Neurosurgical Focus 2004;16(4):1-9.
15. Day JD. Surgical approach to suprasellar and parasellartumors. Neurosurg Clin N Am 2003; 14: 109-22.

16. Aydin JH, Takci E, Kadioglu HH, Kayaoglu CR, Tuzun Y. Pitfalls in the peritoneal approach to the parasellar areas (review). Minim Invasive Neurosurg 2005; 38: 146-52.

17. Vile CJD, Grant DB, Kendall BE, Neville BGR, Sanhope R, Watkins KE, et al. Management of childhood craniopharyngioma: can be morbidity of radical surgery be predicted? J Neurosurg 1996; 85: 73-81.

18. Shirane R, Su CC, Yasukokusaka, Jokura H, YoshimotoT. Surgical outcome in 31 patients with Craniopharyngioma extending outside the suprasellar cistern; an evaluate of the frontobasal Interhemispheric approach. J Neurosurg 2002; 96: 704-12

19. Khan I, Ali S, Mehmood S. Outcome of surgery in sellar and suprasellar tumors using subfrontal approach. PJMHS 2020; 14(1): 664-5.

20. Baskin DS, Wilson CB. Surgical management of craniopharyngiomas: a review of 74 cases. J Neurosurg 1986; 65: 22-7

21. Mahmood RZ, Bajwa I, Zunair SA, Ahmad T, Sultan H, Mehmood S. Surgical outcome of sellar suprasellar brain tumours through retracterless subfrontal approach. Pak J Neurol Surg 2021; 25(1): 43-8.

22. Yasargil MG, Curcic M, Kis M, Siegenthaler G, Teddy PJ, Roth P. Total removal of craniopharyngiomas: approaches and long term results in 144 patients. J Neurosurg 1990; 73: 3-11

23. Sharma BS, Sawarkar DP. Changing trends in surgery for suprasellar lesions. Neurol India 2018; 66:4-8

24. Koutourousiou M, Fernandez-Miranda JC, Stefko ST, Wang EW, Snyderman $\mathrm{CH}$, Gardner PA. Endoscopic endonasal surgery for suprasellar meningiomas: experience with 75 patients. J Neurosurg 2014;120:1326-39.

25. Tan SH, Brand Y, Prepageran N, Waran V. Endoscopic transnasal approach to anterior and middle cranial base lesions. Neurol India 2015;63:673-80.

26. Solari D, Morace R, Cavallo LM, Amoroso F, Cennamo G, Del Basso De Caro $M$, et al. The endoscopic endonasal approach for the management of craniopharyngiomas. J Neurosurg Sci 2016; 60:454-62.

27. Shirane R, Hayashi T, Tominaga T. Fronto-basal interhemispheric approach for craniopharyngiomas extending outside the suprasellar cistern. Childs Nerv Syst 2005; 21, 669-78. 